\title{
Fito-bioterapia no controle de nematódeos gastrointestinais de ovinos
}

\section{Phyto-biotherapy to control gastrointestinal nematodes of sheep}

\author{
Luciane Holsback $^{1 *}$; Petrônio Pinheiro Porto ${ }^{1}$; Ellen de Souza Márquez ${ }^{1}$; \\ Emília de Paiva Porto ${ }^{1}$
}

\begin{abstract}
Resumo
A resistência parasitária e a tendência dos últimos anos de mudança para sistemas orgânicos tem resultado em diversas alternativas de manejo animal como a seleção de raças resistentes, integração com outras espécies animais, fitoterapia, fungos nematófagos, vacinas contra nematódeos, entre outros. Visando uma alternativa para controle da verminose ovina, objetivou-se analisar o efeito da administração de larvas inativadas de Haemonchus associadas ou não a alho in natura no controle de nematódeos gastrointestinais em ovinos naturalmente infectados. Para tanto, 32 ovinos foram avaliados por até 144 dias após tratamentos com larvas inativadas de Haemonchus e/ou alho in natura, quanto à diminuição da eliminação de ovos nas fezes (taxa de Redução na Contagem de Ovos nas Fezes - RCOF), eficiência destes tratamentos sob os gêneros de helmintos e alterações hematológicas. Observou-se aumento significativo na contagem de OPG dos grupos G1 (controle) e G4 (alho in natura). Ao final do experimento observou-se menor contagem de OPG no G3 (larvas inativadas + alho in natura) em relação ao G1, mas sem diferença significativa entre o G3 e os outros tratamentos. Quanto a RCOF, verificou-se redução média de $44 \%$ na contagem de ovos do grupo G2 (larvas inativadas) e do grupo G3 e um aumento de $44 \%$ no grupo G4. A eficácia dos tratamentos sob o gênero Haemonchus variou de 0 a 77\%, sendo esta ultima taxa observada 67 dias no G3, justamente 7 dias depois de observado aumento significativo de linfócitos. Concluiu-se neste estudo que o alho in natura administrado na concentração de $2,5 \mathrm{mg} / \mathrm{Kg}$ não foi capaz de reduzir a carga parasitária dos ovinos, mas que, quando associado a administração de larvas inativadas de Haemonchus pode ter contribuído como imunoestimulante e que a redução dos ovos eliminados nas fezes dos ovinos tratados com larvas inativadas, apesar de insuficiente para ser considerado um método de controle eficaz, demonstra a possibilidade de viabilidade no uso de vacinas contra Haemonchose.
\end{abstract}

Palavras-chave: Fitoterapia, bioterapia, verminose, pequenos ruminantes

\begin{abstract}
The parasitic resistance and the tendency of recent years to shift to organic systems has resulted in several alternative animal management as the selection of resistant breeds, integration with other animal species, phytotherapy, nematophagous fungi, nematodes vaccines, among others. Looking for an alternative control of nematode parasites of sheep, this paper aimed to analyze the effect of administration of inactivated larvae of Haemonchus and fresh garlic on the level infection with gastrointestinal nematodes in naturally infected sheep. Therefore, 32 animals were monitored for 144 days after phyto-biotherapy treatments in relation to reduction of parasite eggs (egg reduction rate - FECR), these treatments under the genres of helminths and hematological changes. It was observed significant increase in the EPGs of G1 (control group) and G4 (fresh garlic). At the end of the experiment observed lower EPG in G3 (inactivated larvae + fresh garlic) compared to G1, but no difference between the EPG of the other
\end{abstract}

\footnotetext{
${ }^{1}$ Profs. da Universidade Estadual do Norte do Paraná, UENP, Bandeirantes, PR. E-mail: 1hsfertonani@uenp.edu.br; petronio@ uenp.edu.br; esmarquez@uenp.edu.br; emilia@uenp.edu.br

* Autor para correspondência
} 
groups. As for FECR, there was an average reduction of $44 \%$ in egg count in G2 (inactivated larvae) and G3 and an increase of $44 \%$ in G4. The effectiveness of the treatments under the genus Haemonchus ranged from 0 to $77 \%$, the latter being rate observed in G3 in day 67 , just 7 days after the significant increase of lymphocytes. It was concluded from this study that fresh garlic administered at $2.5 \mathrm{mg}$ / $\mathrm{kg}$ concentration failed to reduce the parasite burden of sheep, but which, when associated with administration of inactivated larvae of Haemonchus may had contributed to immune stimulant and reduction of eggs eliminated in the faeces of sheep treated with inactivated larvae, though not enough to be considered an effective treatment, the study highlights the importance and use of vaccines to control this parasite.

Key words: Phytotherapy, biotherapy, parasitosis, small ruminants

\section{Introdução}

A ovinocultura é uma atividade largamente explorada para produção de lã, leite e, principalmente, carne. Atualmente o Brasil possui um efetivo de mais de 16,8 milhões de cabeças de ovinos distribuídas principalmente nas regiões Nordeste e Sul do país, com destaque para o Rio Grande do Sul, que detém 23,5\% do total de animais (IBGE, 2006).

Estes pequenos ruminantes são acometidos por inúmeros problemas sanitários, sendo as endoparasitoses gastrintestinais o principal obstáculo para o desenvolvimento da ovinocultura. O parasitismo é ocasionado, principalmente, por espécies de nematódeos gastrintestinais pertencentes à família Trichostrongylidae, sendo 80\% da carga parasitária composta por Haemonchus contortus (GIRÃO; MEDEIROS; GIRÃO, 1992; AROSEMENA et al., 1999). Além deste, outros nematódeos ocupam lugar de destaque como Trichostrongylus colubriformis, Strongyloides spp. Cooperia curticei e Oesophagostomum columbianum (AMARANTE et al., 1997; AMARANTE et al. 2004). Estes parasitos são responsáveis por reduzir a produção de carne e leite em ruminantes, além de lã em ovinos e aumento da mortalidade nos animais jovens (MOLENTO; PRICHARD, 1999).

Otratamento da verminose em ovinosé, na maioria das vezes, realizado exclusivamente com antihelmínticos sintéticos, de forma pouco criteriosa, provocando rapidamente seleção de populações de helmintos resistentes e inviabilizando o controle na propriedade, uma vez que essa resistência pode ser transmitida às gerações seguintes (SOCCOL et al., 1996).

O aparecimento da resistência aos antihelmínticos e a tendência dos últimos anos de mudança para sistemas orgânicos de produção requerem alternativas para redução ou até a exclusão das drogas anti-helmínticas no controle parasitário (ATHANASIADOU et al., 2000).

Visando diminuir os efeitos do uso indiscriminado de anti-helmínticos, diversas alternativas de manejo animal têm sido propostas, a exemplo da seleção de raças resistentes, integração com outras espécies animais, fitoterapia, bioterapia, fungos nematófagos (HASHMI; CONNAN, 1989), utilização de pastoreio alternado e higienização das pastagens (MOTA; CAMPOS; ARAÚJO, 2003), vacinas contra nematódeos (MEEUSEN, 1996), controle biológico (LARSEN, 1999), forragens contendo taninos (BUTTER et al, 2000) e medicamentos homeopáticos (NEVES et al., 2012).

Os nematódeos gastrintestinais induzem resposta imune nos hospedeiros, cuja resistência pode ser definida como a capacidade de impedir ou dificultar o estabelecimento das larvas. As infecções por nematódeos gastrintestinais são crônicas, e uma resposta imune completa, dirigida aos vários estádios parasitários, demora, em geral, vários meses para se desenvolver (TIZARD, 2002).

Dentre os métodos de controle bioterápicos, a vacinação vem apresentando resultados promissores 
a partir da utilização de antígenos de helmintos de ovinos (JASMER; McGUIRE,1996). Antígenos naturais foram identificados a partir de larvas de $3^{\circ}$ e $4^{\circ}$ estágio (NEWTON et al., 1995) e também de adultos (CUQUERELLA et al., 1994).

Muitas plantas são tradicionalmente conhecidas como detentoras de alguma atividade antihelmíntica, entretanto suas eficácias devem ser comprovadas cientificamente. Dentre as inúmeras espécies de plantas que podem substituir medicamentos sintéticos segundo o Sistema Único de Saúde, o Allium sativum L. mostra-se como uma das mais eficazes (MICHELES, 2004; KATZUNG et al., 2003). A atividade terapêutica do alho é demasiadamente extensiva podendo ser utilizada como imunoestimulante, anticancerígena, hepatoprotetora, antioxidante, antiviral, antifúngica e antiparasitária (KATZUNG, 2003; KEMPER, 2000).

Visando avaliar um controle alternativo da verminose ovina, este trabalho teve como objetivo analisar o efeito da administração de alho in natura isolado ou em conjunto com larvas inativadas de Haemonchus no nível de infecção por nematódeos gastrintestinais em ovinos naturalmente infectados.

\section{Material e Métodos}

O experimento foi realizado no município de Bandeirantes, norte do Paraná, nos meses de agosto a novembro de 2009. Para tanto, 32 ovelhas recémdesmamadas, não prenhas, sem raça definida, naturalmente infectadas e criadas sob sistema extensivo de pastejo, foram divididas em quatro grupos experimentais, após randomização pela OPG (média 170), sendo; Grupo 1 (G1) - 8 ovelhas não tratadas (controle); Grupo 2 (G2) - 8 ovelhas que receberam 800 larvas L3 de Haemonchus inativadas/dia por via oral, durante três dias (dias -3, -2 e -1); Grupo 3 (G3) - 8 ovelhas que receberam 800 larvas de Haemonchus L3 inativadas/dia por via oral, durante três dias (dias $-3,-2$ e -1) + 2,5g/ $\mathrm{Kg}$ PV de alho in natura, por 6 dias (dias $-6,-5$,
$-4,-3,-2$ e -1$)$ e Grupo 4 (G4) - 8 ovelhas que receberam alho in natura por 6 dias (dias -6, -5, $-4,-3,-2$ e -1). As larvas foram obtidas através de coproculturas realizadas de amostras de fezes dos animais utilizados nos grupos experimentais 3 meses antes do início do experimento. Para obtenção das larvas de Haemonchus os animais foram tratados previamente com ivermectina $1 \%(200 \mu \mathrm{g} / \mathrm{Kg}, \mathrm{SC}$, dose única), pois a resistência de Haemonchus a este anti-helmíntico era conhecido na propriedade. Após lavagens sucessivas das larvas recolhidas com água estéril e centrifugação (2.500 RPM/5 minutos, 10 repetições), as mesmas foram quantificadas e conservadas a $4^{\circ} \mathrm{C}$ até sua utilização. Um dia antes aos tratamentos as larvas foram quantificadas novamente, diluídas na concentração de 400 larvas/ $\mathrm{mL}$ de solução, e cada dose $(2 \mathrm{~mL})$ foi congelada por 24 horas a $-15^{\circ}$ individualmente. No dia (manhã) do tratamento, as amostras, ainda congeladas, foram submergidas em água a $80^{\circ} \mathrm{C}$ por 20 segundos. Após este choque térmico pequena alíquota das doses foram visualizadas a microscopia ótica comum para verificação de inviabilidade das larvas, demostrada pelas suas imobilidades após 20 minutos.

Todos os 32 animais receberam a mesma quantidade de ração concentrada, fornecida pela manhã em pequena quantidade (500g/animal). Nos dias da administração do alho in natura para os grupos G3 e G4 os animais permaneciam no aprisco até consumirem todo o alho, período este que correspondeu há aproximadamente 1,5 horas ao dia, nos seis dias de administração do produto. Após o consumo, eles retornavam ao piquete. Os tratamentos foram repetidos 60 e 120 dias depois. A água foi fornecida ad libitum e todos os animais foram mantidos no mesmo piquete.

Amostras de fezes de todos os animais dos quatro grupos foram coletados nos dias -6 (antes aos tratamentos), 7, 24, 60, 67, 84, 120, 127 e 144 dias após o último dia do tratamento, para contagem de ovos por grama de fezes (OPG) pela técnica de Gordon e Withlock (1939), avaliação da Redução da Contagem de Ovos nas Fezes (RCOF), de acordo 
com Coles et al. (1992) e coprocultura de acordo com a Técnica de Roberts e O'Sulivan (1950). As larvas (L3) foram identificadas de acordo com os critérios de Keith (1953). A eficácia dos tratamentos nos diferentes dias avaliados e sob cada gênero de nematódeo identificado foi calculada pela fórmula:

Eficácia sob gênero X = (média LPG de X do GC - média LPG de X do GT) x 100 média $\mathrm{LPG}$ de $\mathrm{X}$ do GC

Onde:

LPG: Larvas por grama de fezes

$\mathrm{X}$ - gênero das larvas identificadas

$\mathrm{GC}$ - grupo controle

GT - grupo tratado

Amostras de sangue de todos os animais foram coletadas nos dias -6, 24, 60, 84, 120 e 144. Realizou-se a contagem global de leucócitos através do método do hemocitômetro e a contagem diferencial foi mensurada, após a obtenção da contagem relativa, em contagem absoluta de leucócitos (HEWITT, 1984). A contagem total de hemácias foi realizada pela técnica do hemocitômetro, concentração da hemoglobina pelo método da cianometahemoglobina e a determinação do volume globular por meio do micro-hematócrito. Para dosagem de proteínas totais, usou-se o reativo de biureto (WEICHSELBAUM, 1946).

Os valores dos OPGs foram transformados em logaritmo $(\log \mathrm{x}+1)$ sendo as médias comparadas pelo teste de "Tukey" e as médias dos valores dos hemogramas comparadas por "Repeated Measures ANOVA". Os testes estatísticos foram realizados pelo programa estatístico GraphPad Prism 5.0.

\section{Resultados e Discussão}

As médias das contagens de ovos por grama de fezes dos ovinos dos grupos controle (G1) e tratado apenas com alho in natura (G4) aumentou significativamente $(p=0,008$ e 0,018 respectivamente) ao final do experimento (dia 144) (Tabela 1).
Tabela 1. Médias \pm Desvio Padrão das contagens de ovos nas fezes (OPG, $\log \mathrm{x}+1)$ dos animais nos dias -6 e 144, dos grupos G1 (controle), G2 (larvas inativadas), G3 (larvas inativadas + alho in natura) e G4 (alho in natura).

\begin{tabular}{lclc}
\hline & \multicolumn{2}{c}{ OPG $(\log x+1) \pm$ Desvio } & \\
\cline { 2 - 3 } GRUPOS & Dia -6 & \multicolumn{1}{c}{ Dia 144} & Valor de $p$ \\
\hline G1 & $2,21( \pm 0,1)$ & $2,90^{*}( \pm 1,16)$ & 0,008 \\
G2 & $2,16( \pm 1,26)$ & $2,63( \pm 1,41)$ & $>0,05$ \\
G3 & $2,18( \pm 1,23)$ & $2,66( \pm 0,36)$ & $>0,05$ \\
G4 & $2,33( \pm 1,27)$ & $3,05^{*}( \pm 0,27)$ & 0,018 \\
\hline
\end{tabular}

* indica diferença significativa $(\mathrm{p}<0,05)$ das médias entre os dias no mesmo grupo (linhas).

Fonte: Elaboração dos autores.

Em relação à comparação das cargas parasitárias entre os grupos experimentais, ao final do experimento observou-se menor OPG no G3 (animais que receberam larvas inativadas + alho in natura) em relação ao G1 $(\mathrm{p}=0,023)$. Apesar das médias dos OPGs dos animais dos grupos G2 e G3 após os tratamentos terem se mantido abaixo dos OPGs dos animais do grupo controle até 120 dias, estas diferenças não foram significativas (Figura 1). 
Figura 1. Distribuição das médias dos OPGs transformados em $\log (\mathrm{x}+1)$ de todos os grupos experimentais (G1, G2, G3, G4) antes aos tratamentos e 7, 24, 60, 67, 84, 120, 127 e 144 dias depois.

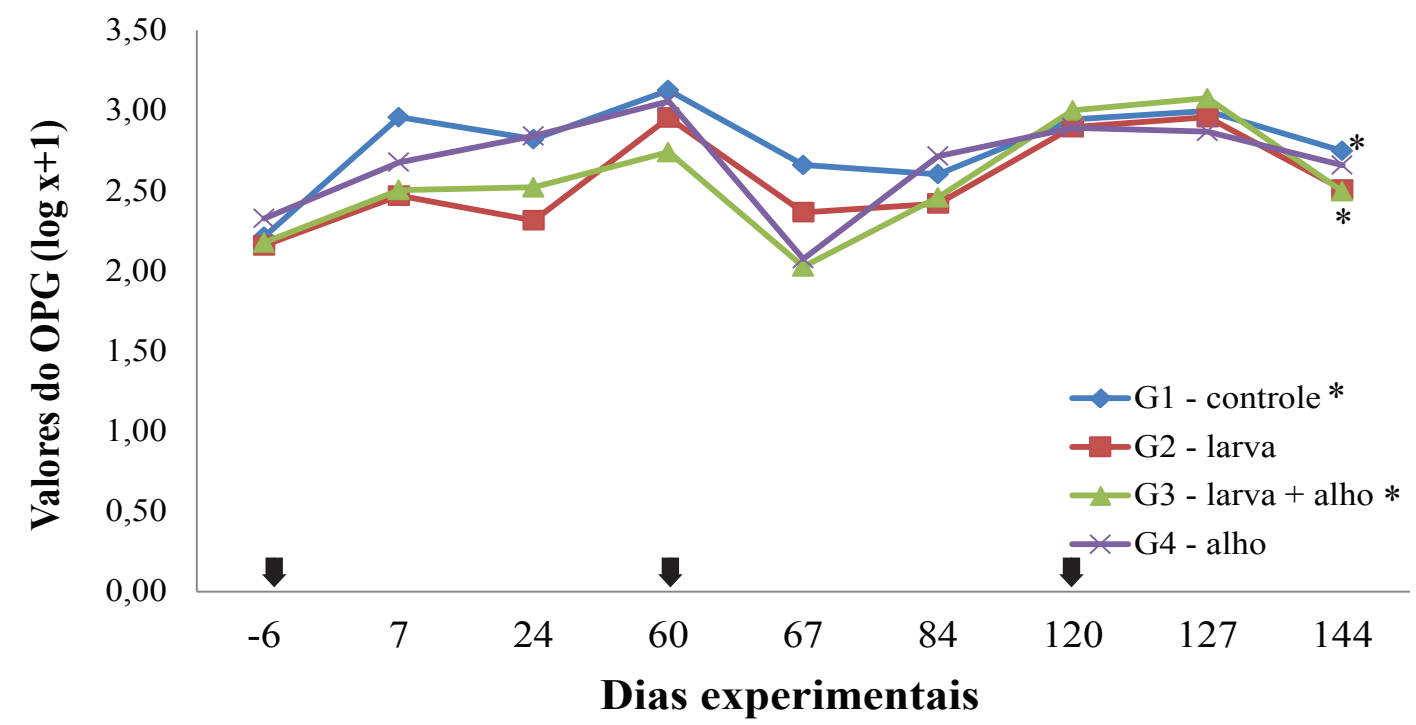

\footnotetext{
* Diferença significativa entre os grupos G1 X G3 no dia 144 ( $p<0,05)$.

Tratamentos dos animais: Dias -6, 60 e 120.

Fonte: Elaboração dos autores.
}

Para o presente estudo, a RCOF foi utilizada não com o intuito de se estimar a resistência dos helmintos aos tratamentos, mas sim, verificar o quanto os tratamentos reduziram a eliminação de ovos de helmintos nas fezes dos animais ao final das avaliações.

Sendo assim, verificou-se que houve uma redução média de $44 \%$ na contagem de ovos do grupo G2 (larvas inativadas) e do grupo G3 (larvas inativadas + alho in natura) e um aumento de $44 \%$ da contagem de ovos do grupo G4, tratado apenas com alho in natura (Tabela 2). Esta redução somada ao menor OPG encontrado no G3 sugere um efeito positivo do tratamento dos ovinos com as larvas inativadas.

Apesar de abaixo dos padrões recomendados pela WAAVP (World Association for the Advancement of Veterinary Parasitology), ressalta-se que muitos anti-helmínticos químicos não reduzem os níveis de infecção parasitária (mesmo poucos dias após o tratamento) aos níveis que os tratamentos dos grupos G2 (46\%) e G3 (41\%) alcançaram 144 dias depois (CUNHA FILHO et al., 1998; SOCCOL et al., 2004; MOLENTO 2004; SCZESNY-MORAES et al., 2010).

A eficiência do Allium sativum no controle da verminose em ruminantes é bastante variada. Bianchin et al. (1999) e Bianchin e Catto (2004) relataram respectivamente taxas médias de redução (RCOF) de 47,3 e 50\% na contagem de ovos de nematódeos nas fezes de bovinos tratados respectivamente com $8 \mathrm{mg} / \mathrm{Kg}$ PV/dia e $30 \mathrm{mg} / \mathrm{Kg}$ $\mathrm{PV} /$ dia de alho desidratado misturado ao sal mineral ou ração. Neste último experimento os pesquisadores não observaram diminuição significativa nas médias dos OPGs do grupo tratado em comparação ao grupo controle. Sunada et al. (2011) também encontraram taxas de RCOF semelhantes e recomendam o alho como um método fitoterápico para o controle de parasitas gastrointestinais de ovinos. A maior RCOF relatada após o uso de variadas concentrações deste fitoterápico ocorreu por Navaneetha, Veerakumari e Raman (2011), sendo a menor, de $96,1 \%$ e a maior de $98,9 \%$ utilizando concentrações respectivamente de $10 \mathrm{mg} \mathrm{mL}^{-1}$ e $30 \mathrm{mg} \mathrm{mL}^{-1}$ de extrato de bulbos de alho. 
Tabela 2. Taxas de Redução na Contagem de Ovos (RCOF) nas fezes dos ovinos do G1 - controle não tratado, G2 - tratados com larvas inativadas, G3 - tratados com larvas inativadas + alho in natura e G4 tratados apenas com alho in natura, de acordo com os valores dos OPGs ao final ao experimento (dia 144).

\begin{tabular}{lcc}
\hline GRUPOS & OPG (dia 144) \pm Erro padrão & RCOF $(\%)$ \\
\hline G1 & $786( \pm 357)$ & - \\
G2 & $425( \pm 245)$ & 46 \\
G3 & $460( \pm 129)$ & 41 \\
G4 & $1133( \pm 269)$ & -44 \\
\hline
\end{tabular}

Fonte: Elaboração dos autores.

Corroborando com a ineficiência do alho encontrada no presente estudo, Batatinha et al. (2004) e Worku, Franco e Baldwin (2009) não encontraram diminuição significativa no OPG de caprinos tratados com suco de alho. Santos, Vogel e Monteiro (2012) utilizando também extrato aquoso de alho, não encontraram alteração na carga parasitária de ovinos naturalmente infectados e tratados com 60 e $90 \mathrm{~g}$ desta planta.

A imunidade específica anti-helmíntica pode ser induzida por vacinações com larvas infectantes irradiadas, com extratos larvares ou com doses elevadas de larvas infectantes (EMERY et al., 1992). A confirmação de que os antígenos intestinais induzem imunidade contra o nematódeo hematófago $H$. contortus foi primeiramente demonstrada com a utilização de uma molécula isolada da superfície do epitélio intestinal de $H$. contortus, denominada de "Contortin". Ovinos imunizados com esse antígeno e desafiados com larvas infectantes de H. contortus, apresentaram redução de $78 \%$ na carga parasitária (MUNN; GREENWOOD; COADWELL, 1987).
Outras proteínas intestinais de Haemonchus foram isoladas apresentando bons índices de redução da carga parasitária. O antígeno H11 (glicopreteína de membrana da superfície microvilar intestinal) com taxas de redução de 92 e 94,6\% (MUNN et al., 1993) e H-gal-GP ("Haemonchus galactose containing glycoprotein complex") demonstrando 92\% de redução na contagem de ovos (SMITH; SMITH; MURRAY, 1994).

Os resultados aqui demonstrados após a administração das larvas inativadas aos ovinos dos grupos G2 e G3 podem ter sido obtidos por estimulação de antígenos específicos do estágio precoce (larva L3) contra parasitas adultos, resultando em diminuição na contagem de ovos mais tardiamente. A irradiação de larvas infectantes de várias espécies de nematódeos hematófagos impede que no hospedeiro ocorra o desenvolvimento do parasita, impedindo desta forma o ciclo de vida do mesmo (JASMER; McGUIRE, 1996). Neste estudo, todavia, a grande variedade e a pouca quantidade de antígenos imunogênicos presentes nas larvas inativadas podem ter colaborado com a baixa eficácia da imunização se comparado à induzida por antígenos purificados (H11, H-gal-GP por exemplo). Apesar de baixa, a imunização pôde ser confirmada através da observação de um aumento significativo $(\mathrm{p}<0,05)$ de linfócitos absolutos 60 dias após a administração das larvas inativadas nos grupos G2 e G3 (Tabela 3), justamente 7 dias antes das menores cargas parasitárias observadas nestes grupos experimentais $(\mathrm{G} 2=231 \mathrm{OPG}$ e G3 $=106$ OPG) que podem ser visualizadas no Gráfico 1 (OPGs transformados em logaritmo). 
Tabela 3. Médias das contagens absolutas de hemácias, leucócitos, linfócitos, eosinófilos, volume globular médio (VG) e proteína total plasmática (PTP) do G1 - controle, G2 - larvas inativas, G3 - larvas inativadas + alho in natura e G4 = alho in natura antes aos tratamentos (dia -6) e 24, 60, 84, 120 e 144 dias depois.

\begin{tabular}{|c|c|c|c|c|c|c|}
\hline & Hemácias & VG (\%) & Leucócitos & Linfócitos & Eosinófilos & PTP \\
\hline RUPO 1 & $(9-15.000 .000)$ & $(28-40)$ & $(4-12.000)$ & $(2-9.000)$ & $(0-1.000)$ & $(5,4-9,0)$ \\
\hline-6 & $8.912 .500^{(\mathrm{a})}$ & $28,3^{-(a)}$ & $9.769^{(\mathrm{a})}$ & $3.143^{(\mathrm{a})}$ & $912^{(\mathrm{a})}$ & $-\overline{6,8^{(\mathrm{a})}}-$ \\
\hline 24 & $9.868 .750^{\text {(a) }}$ & $32,3^{\text {(a) }}$ & $10.663^{\text {(a) }}$ & $4.171^{\text {(a) }}$ & $2.823^{\text {(a) }}$ & $7,0^{\text {(a) }}$ \\
\hline 60 & $9.681 .250^{\text {(a) }}$ & $32,5^{\text {(a) }}$ & $11.000^{\text {(a) }}$ & $3.584^{(\mathrm{a})}$ & $1.394^{\text {(a) }}$ & $6,0^{\text {(a) }}$ \\
\hline 84 & $6.992 .500^{\text {(a) }}$ & $28,8^{\text {(a) }}$ & $7.488^{\text {(a) }}$ & $3.014^{\text {(a) }}$ & $579^{\text {(a) }}$ & $7,0^{\text {(a) }}$ \\
\hline 120 & $6.722 .500^{\text {(a) }}$ & $31,3^{\text {(a) }}$ & $8.309^{\text {(a) }}$ & $3.468^{\text {(a) }}$ & $1.072^{\text {(a) }}$ & $6,0^{\text {(a) }}$ \\
\hline 144 & $-7.057 .500{ }^{(a)}$ & $\underline{30,4} \underline{-}_{-}^{\text {(a) }}$ & 9.43ㄴ. (a) & $3.395{ }^{\text {(a) }}$ & $1.040_{-}^{(\mathrm{a})}$ & $\underline{6}, \underline{0}^{(\mathrm{a})}$ \\
\hline-6 & $9.595 .0000^{(\mathrm{a})}$ & $29,6^{(a)}$ & $11.681^{-(a)}$ & $3.280^{(\mathrm{a})}$ & $-\overline{4.488^{(a)}}$ & $\overline{7,8^{(a)}}$ \\
\hline 24 & $11.268 .750^{\text {(a) }}$ & $33,9^{\text {(a) }}$ & $11.255^{\text {(a) }}$ & $4.191^{\text {(a) }}$ & $2.666^{\text {(a) }}$ & $7,6^{\text {(a) }}$ \\
\hline 60 & $10.606 .250^{\text {(a) }}$ & $32,6^{(a)}$ & $13.188^{\text {(a) }}$ & $5.694^{(\mathrm{b})}$ & $1.704^{\text {(a) }}$ & $7,0^{\text {(a) }}$ \\
\hline 84 & $6.921 .250^{\text {(a) }}$ & $27,6^{\text {(a) }}$ & $8.619^{\text {(a) }}$ & $3.006^{\text {(a) }}$ & $512^{\text {(a) }}$ & $7,2^{\text {(a) }}$ \\
\hline 120 & $5.885 .000^{\text {(a) }}$ & $32,0^{\text {(a) }}$ & $9.806^{(\mathrm{a})}$ & $4.150^{(\mathrm{a}, \mathrm{c})}$ & $1.321^{\text {(a) }}$ & $6,9^{\text {(a) }}$ \\
\hline 144 & $6.987 .500^{\text {(a) }}$ & $33,0^{\text {(a) }}$ & $9.488^{\text {(a) }}$ & $4.289^{(\mathrm{b}, \mathrm{c})}$ & $936^{\text {(a) }}$ & $6,5^{\text {(a) }}$ \\
\hline \multicolumn{7}{|l|}{ GRUPO 3} \\
\hline-6 & $9.024 .286^{\text {(a) }}$ & $29,1^{(:}$ & $9.850^{(\mathrm{a}}$ & 2.530 & 1.655 & 7,5 \\
\hline 24 & $10.765 .714^{\text {(a) }}$ & $33,3^{\text {(a) }}$ & $11.900^{\text {(a) }}$ & $5.287^{\text {(a) }}$ & $2.765^{\text {(a) }}$ & $7,1^{\text {(a) }}$ \\
\hline 60 & $11.588 .571^{\text {(a) }}$ & $32,6^{\text {(a) }}$ & $17.657^{\text {(a) }}$ & $8.039^{(b)}$ & $2.940^{\text {(a) }}$ & $6,6^{\text {(a) }}$ \\
\hline 84 & $7.364 .286^{(a)}$ & $25,7^{\text {(a) }}$ & $9.971^{\text {(a) }}$ & $5.023^{(\mathrm{a}, \mathrm{b})}$ & $366^{\text {(a) }}$ & $7,0^{\text {(a) }}$ \\
\hline 120 & $5.711 .429^{\text {(a) }}$ & $28,9^{\text {(a) }}$ & $11.671^{\text {(a) }}$ & $4.544^{(\mathrm{a}, \mathrm{b})}$ & $1.391^{\text {(a) }}$ & $6,7^{\text {(a) }}$ \\
\hline 144 & $7.542 .857_{-}^{\text {(a) }}$ & $33,9_{-}^{\text {(a) }}$ & $10.664_{-}^{\text {(a) }}$ & $5.846_{-}^{(\mathrm{b})}$ & $1.074{ }_{-}^{(a)}$ & $-{ }_{-1}{ }_{-}^{\text {(a) }}$ \\
\hline \multicolumn{7}{|c|}{ GRUPOO 4 } \\
\hline-6 & 8.563 .750 & $25,4^{(a)}$ & $9.850^{(a)}$ & $2.973^{(\mathrm{a})}$ & $337^{(\mathrm{a})}$ & $7,3^{(a)}$ \\
\hline 24 & $9.583 .750^{\text {(a) }}$ & $30,8^{\text {(a) }}$ & $11.900^{\text {(a) }}$ & $5.250^{(\mathrm{a}, \mathrm{b})}$ & $841^{\text {(a) }}$ & $6,9^{\text {(a) }}$ \\
\hline 60 & $10.352 .500^{(a)}$ & $30,8^{(\mathrm{a})}$ & $17.657^{\text {(a) }}$ & $4.596^{(\mathrm{a}, \mathrm{b})}$ & $663^{\text {(a) }}$ & $6,5^{(a)}$ \\
\hline 84 & $7.160 .000^{\text {(a) }}$ & $27,9^{\text {(a) }}$ & $9.971^{\text {(a) }}$ & $2.707^{(\mathrm{b})}$ & $612^{\text {(a) }}$ & $7,2^{\text {(a) }}$ \\
\hline 120 & $7.683 .750^{\text {(a) }}$ & $28,4^{\text {(a) }}$ & $11.671^{\text {(a) }}$ & $4.533^{(\mathrm{a}, \mathrm{b})}$ & $343^{\text {(a) }}$ & $6,5^{\text {(a) }}$ \\
\hline 144 & $6.840 .000^{\text {(a) }}$ & $30,9^{\text {(a) }}$ & $10.664^{\text {(a) }}$ & $5.103^{(\mathrm{a}, \mathrm{b})}$ & $370^{\text {(a) }}$ & $6,2^{\text {(a) }}$ \\
\hline
\end{tabular}

$\mathrm{VG}=$ volume globular médio; PTP $=$ proteína total plasmática.

Letras distintas na mesma coluna, dentro do mesmo grupo, representam diferenças significativas $(\mathrm{p}<0,05)$.

Fonte: Elaboração dos autores.

Em ovinos expostos a infecções diárias com Trichostrongylus colubriformis, Haemonchus contortus ou Ostertagia circumcincta (1.000 a 2.000 larvas infectantes por dia) por 5-6 semanas, o desenvolvimento das larvas infectantes torna-se tardio. A fecundidade de adultos de $T$. colubriformis é reduzida após 10-12 semanas e a expulsão dos helmintos adultos ocorre de 16 a 20 semanas (DOBSON; WALLER; DONALD, 1990). Em H.contortus, a produção de ovos e a carga parasitária estão intimamente associadas e ambas diminuem após 20-24 semanas de ingestão 
contínua de larvas (BARGER et al., 1985).

A eficácia dos tratamentos sob o gênero Haemonchus variou de 0 a $77 \%$, sendo esta ultima taxa observada 67 dias no G3, grupo tratado com as larvas inativadas + alho in natura. Vale lembrar que os tratamentos foram repetidos no dia $60 \mathrm{e}$ 120 , sendo possível que a readministração das larvas inativadas de Haemonchus aos animais deste grupo, somada ao efeito imunoestimulatório do alho, tenha gerado esta eficiência de $77 \%$ sob este gênero, já que a eficiência do outro gênero encontrado, Cooperia, neste mesmo dia, foi de apenas $42 \%$. Reforça esta hipótese os dois picos de aumento significativo de linfócitos encontrados no G3 nos dias 60 e 144 (Tabela 3).

\section{Conclusão}

Concluiu-se neste estudo que o alho in natura administrado na concentração de $2,5 \mathrm{mg} / \mathrm{Kg}$ não foi capaz de reduzir a eliminação de ovos pelas fezes dos ovinos, mas que, quando associado a administração de larvas inativadas de Haemonchus pode ter contribuído como um imunoestimulante e que a redução de $46 \%$ dos ovos eliminados nas fezes dos ovinos tratados com larvas inativadas, apesar de insuficiente para ser considerado um tratamento eficaz, demonstra a possibilidade de viabilidade no uso de vacinas contra Haemonchose.

Este trabalho foi aprovado pela Comissão de Ética no Uso de Animais (CEUA) desta Instituição e realizado de acordo com as normas técnicas de biossegurança e ética (protocolo 1017-40 - CEUA/ UENP).

\section{Agradecimentos}

A Fundação Araucária pelo apoio financeiro.

\section{Referências}

AMARANTE, A. F. T.; BAGNOLA, J. R. J.; AMARANTE, M. R. V.; BARBOSA, M. A Host specificity of sheep and cattle nematodes in São Paulo state, Brazil. Veterinary Parasitology, Amsterdam, v. 73, n. 1-2, p. 89-104, 1997.

AMARANTE, A. F. T.; BRICARELLO, P. A.; ROCHA, R. A.; GENNARI, S. M. Resistance of Santa Inês, Suffolk and Ile de France lambs to naturally acquired gastrointestinal nematode infections. Veterinary Parasitology, Amsterdam, v. 120, n. 1-2, p. 91-106, 2004.

ARosemenA, N. A. E.; BEVILAQUA, C. M. L.; MELO, A. C. F. L.; GIRÃO, M. D. Seasonal variations of gastrointestinal nematodes in sheep and goats from semi-arid area in Brazil. Revue de Médecine Vétérinaire, v. 150, n. 11, p. 873-876, 1999.

ATHANASIADOU, S.; KYRIAZAKIS, I.; JACKSON, F.; COOP, R. L. Consequences of long-term feeding with condensed tannins on sheep parasited with Trichostrongylus colubriformis. International Journal Parasitology, v. 30, n. 9, p. 1025-1033, 2000.

BARGER, I. A.; LEJAMBRE, L. F.; GEROGI, J. R.; DAVIES, H. I. Regulation of Haemonchus contortus populations in sheep exposed to continuous infection. International Journal for Parasitology, Oxford, v. 15, n. 5, p. 529-534, 1985.

BATATINHA, M. J. M.; BOTURA, M. B.; SANTOS, M. M.; SILVA, A.; ALMEIDA, M. G. A. R.; SANTANA, A. F.; BITTENCOURT, T. C. B. S. C.; ALMEIDA, M. A. O. Efeitos do suco de alho (Allium sativum Linn.) sobre nematódeos gastrintestinais de caprinos. Ciência Rural, Santa Maria, v. 34, n. 4, p. 1265-1266, 2004.

BIANCHIN, I.; CATTO, J. B. Alho desidratado (Allium sativum L.) no controle de nematódeos gastrintestinais em bovinos naturalmente infectados. Ciência Rural, Santa Maria, v. 34, n. 4, p. 170-77, 2004.

BIANCHIN, I.; GOMES, A.; FEIJÓ, G. L. D.; VAZ, E. C. Eficiência do pó de alho (Allium sativum) no controle dos parasitos de bovinos. Campo Grande: [s.n], 1999. 31 p. (Boletim de Pesquisa Embrapa Gado de Corte, n. 8).

BUTTER, N. L.; DAWSON, J. M.; WAKELIN, D.; BUTTERY, P. J. Effect of dietary tannin and protein concentration on nematode infection Trichostrongyus colubriformis in lambs. Journal of Agricultural Science, Cambridge, v. 134, p.89-90, 2000.

COLES, G. C.; BAUER, C.; BORGSTEEDE, F. H.; GEERTS, S.; KLEI, T. R.; TAYLOR, M. A.; WALLER, P. J. World Association for the Advancement of Veterinary Parasitology (WAAVP) methods for the detection of anthelmintic resistance in nematodes of veterinary importance. Veterinary Parasitology, Amsterdam, v. 44, n. 1-2, p. 35-44, 1992. 
CUNHA FILHO, L. F. C.; PEREIRA, A. B. L.; YAMAMURA, M. H. Resistência a anti-helmínticos em ovinos na região de Londrina - Paraná - Brasil. Semina: Ciências Agrárias, Londrina, v. 19, n. 1, p. 31-37, 1998.

CUQUERELLA, M.; GÓMEZ-MUÑHOZ, M. T.; CARRERA, L.; FUENTE, C.; ALUNDA, J. M. Cross antigenicity among ovine trichotrongyloidea. Preliminary report. Veterinary Parasitology, Amsterdam, v. 53, n. 3-4, p. 243-251, 1994.

DOBSON, R. J.; WALLER, P. J.; DONALD, A. D. Population dynamics of Trichostrongylus colubriformis in sheep: the effect of infection rate on the establishment of infective larvae and parasite fecundity. International Journal for Parasitology, Oxford, v. 20, n. 3, p. 347-352, 1990.

EMERY, D. L.; MCCLURE, S. J.; WAGLAND, B. M.; JONES, W. O. Studies of stage-specific immunity against Trichostrogylus colubriformis in sheep: immunization with normal and truncated infections. International Journal for Parasitology, Oxford, v. 22, n. 2, p. 221-215, 1992.

GIRÃO, E. S.; MEDEIROS, L. P.; GIRÃO, R. N. Ocorrência e distribuição sazonal de helmintos gastrintestinais de caprinos no Município de Teresina, Piauí. Ciência Rural, Santa Maria, v. 22, n. 2, p. 197202, 1992.

GORDON, H. M. C. L.; WHITLOCK, H. V. A new technique for counting nematode eggs in sheep faeces. Journal Council Scientific Industrial Australia, Melbourne, Australia, v. 12, n. 1, p. 50-52, 1939.

HASHMI, H. A.; CONNAN, R. M. Biological control of ruminant Trichostrongilids by Arthrobotrys oligospora, a predacious fungus. Parasitology Today, Cambridge, v. 5, n. 1, p. 28-30, 1989.

HEWITT, S. G. Haematology. In: GRAY, D. E. Manual of veterinary investigation, laboratory techniques. 3. ed. London: Her Majesty's Stationery Office, 1984. p. 72100.

INSTITUTO BRASILEIRO DE GEOGRAFIA E ESTATÍSTICA - IBGE. Censo agropecuário 2006. Distrito Federal: IBGE, 2006. Disponível em: <http://www.ibge.gov.br/home/estatistica/economia/ agropecuaria/censoagro/agri_familiar_2006/familia_ censoagro2006.pdf $>$. Acesso em: 16 maio 2013.

JASMER, D. P.; McGUIRE, T. C. Antigens with application toward immune control of blood-feeding parasitic nematodes. British Veterinary Journal, London, v. 152 , n. 3, p. 251-268, 1996.

KATZUNG, B. G. Farmacologia básica e clínica. 8. ed. Rio de Janeiro: Guanabara Koogan, 2003.
KEITH, R. K. The differenciation of the infective larval of some common nematode parasites of cattle. Aust. J. Zool., v. 1, p. 223-230, 1953.

KEMPER, K. J. Garlic (Allium sativum). 2000. Disponível em: <http://www.longwoodherbal.org/garlic/ garlic.pdf>. Acesso em: 14 jun. 2013.

LARSEN, M. Biological control of helminths. International Journal for Parasitology, Oxford, v. 29, n. 1, p. 139-146, 1999.

MEEUSEN, E. Rational design of nematode vaccinesnatural antigens. International Journal of Parasitology, Oxford, v. 26, n. 8-9, p. 813-818, 1996.

MICHELES, E. Fitoterapia como prática institucional: a experiência do Estado do Rio de Janeiro. Jornal Brasileiro de Fitomedicina, Itajaí, v. 2, n. 1-4, p. 1-4, 2004.

MOLENTO, M. B. Multidrug resistance in Haemonchus contortus associated with suppressive treatment and rapid drug alternation. Revista Brasileira de Parasitologia Veterinária, Jaboticabal, v. 13, p. 272, 2004.

MOLENTO, M. B.; PRICHARD, R. K. Nematode control and the possible development of anthelmintic resistance. Revista Brasileira de Parasitologia Veterinária, Jaboticabal, v. 8, n. 1, p. 75-86, 1999.

MOTA, A. M.; CAMPOS, A. K.; ARAÚJO, V. J. Controle biológico de helmintos parasitos de animais: estágio atual e perspectivas futuras. Pesquisa Veterinária Brasileira, Seropédica, v. 23, n. 3, p. 93-100, 2003.

MUNN, E. A.; GREENWOOD, C. A.; COADWELL, W. J. Vaccination of young lambs by means of a protein fraction extracted from adult Haemonchus contortus. Parasitology, Cambridge, v. 94, n. 2, p. 385-397, 1987.

MUNN, E. A.; SMITH, T. S.; GRAHAM, M.; GREENWOOD, C. A.; TAVERNOR, A. S.; COETZEE, G. Vaccination of Merino lambs against haemonchosis with membrane-associated proteins from the adult parasite. Parasitology, Cambridge, v. 106, n. 1, p. 63-66, 1993.

NAVANEETHA, L. K.; VEERAKUMARI, L.; RAMAN, M. Efficacy of Allium sativum Linn. against strongyles in naturally infected sheep. Journal of Veterinary Parasitology, Amsterdam, v. 25, n. 2, p. 124-128, 2011.

NEVES, H. H.; HOTZEL, M. J.; HONORATO, L. A.; FONSECA, C. E. M.; MATA, M. G. F.; SILVA, J. B. Controle de verminoses gastrintestinais em caprinos utilizando preparados homeopáticos. Revista Brasileira de Agroecologia, Cruz Alta, v. 7, n. 1, p. 145-151, 2012.

NEWTON, S. E.; MORRISH, L. E.; MARTIN, P. J.; MONTAGUE, P. E.; ROLPH, T. P. Protection against 
multiply drug-resistant and geographically by vaccination with H11, a gut membrane-derived protective antigen. International Journal for Parasitology, Oxford, v. 25, n. 4, p. 511-521, 1995.

ROBERTS, F. H. S.; O'SULLIVAN, J. P. Methods for egg counts and larval cultures for strongyles infesting the gastrointestinal tract of cattle. Australian Agriculture Research, Australia, v. 1, n. 1, p. 99-102, 1950.

SANTOS, F. C. C.; VOGEL, F. S. F.; MONTEIRO, S. G. Extrato aquoso de alho (Allium sativum) sobre nematóides gastrintestinais de ovinos. Revista Brasileira de Agroecologia, Cruz Alta, v. 7, n. 1, p. 139-144, 2012.

SCZESNY-MORAES, E. A.; BIANCHIN, I.; DA SILVA, K. F.; CATTO, J. B.; HONER, M. R.; PAIVA, F. Resistência anti-helmíntica de nematódeos gastrintestinais em ovinos, Mato Grosso do Sul. Pesquisa Veterinária Brasileira, Seropédica, v. 30, n. 3, p. 229236, 2010.

SMITH, W. D.; SMITH, S. K.; MURRAY, J. M. Protection studies with integral membrane fractions of Haemonchus contortus. Parasite Immunology, Oxford, v. 16, n. 5, p. 231-241, 1994.

SOCCOL, V. T.; SOTOMAIOR, C.; SOUZA, F. P.; CASTRO, E.A.; PESSÔA SILVA, M. C.; MILCZEWSKI, $\mathrm{V}$. Occurrence of resistance to anthelmintic in sheep in
Paraná State, Brazil. The Veterinary Record, London, v. 139, n. 17, p. 421- 422, 1996.

SOCCOL, V. T.; De SOUZA, F. P.; SOTOMAIOR, C.; CASTRO, E. A.; MILCZEWSKI, V.; MOCELIN, G.; PESSOA, E.; SILVA, M. C. Resistance of gastrointestinal nematodes to anthelmintics in sheep (Ovis aries). Brazilian Archives of Biology and Technolology, v. 47, n. 1, p. 41-47, 2004.

SUNADA, N. S.; ORRICO JUNIOR, M. A. P.; ORRICO, A. C. A.; OLIVEIRA, A. B. M.; CENTURION, S. R.; LIMA, S. R. N.; FERNANDES, A. R. M.; VARGAS JUNIOR, F. M. Control parasite using levamizol, ivermectin and dehydrated garlic (Allium sativum) in sheep race Santa Inês. Revista Agrarian, Dourados, MS, v. 4, n. 12, p. 140-145, 2011.

TIZARD, I. R. Imunologia veterinária. 6. ed. São Paulo: Roca, 2002. 548 p.

WEICHSELBAUM, C. T. E. An accurate and rapid method for determination of proteins in small amounts of blood serum and plasma. American Journal of Clinical Pathology, United States, v. 10, p. 40-49, 1946.

WORKU, M.; FRANCO, R.; BALDWIN, K. Efficacy of garlic as an anthelmintic in adult boer goats. Archives of Biological Sciences, Belgrade, v. 61, n. 1, p. 135-140, 2009. 